\section{IMAGINAÇÃO MUSICAL, MELANCOLIA E GOTA NA FILOSOFIA DE GIROLAMO CARDANO}

\author{
Jacomien Prins*
}

RESUMO: Girolamo Cardano (1501-1576) ainda não atraiu a atenção acadêmica merecida por sua teoria sobre a coincidência entre a música, a medicina e a matemática. Como teórico musical e médico, Cardano frequentemente se concentra em fenômenos que considera ser os mais sutis e difíceis de entender. Entre estes, encontra-se a doutrina platônica sobre o poder da música ao influenciar o corpo e a alma humanos. Este artigo explora a interpretação desta doutrina específica, aprofundando-se em sua recepção da medicina galênica, da tradição da musica humana e especialmente da teoria da mágica musical de Marsilio Ficino. Além disto, trata da crítica de Julius Caesar Escalígero (1484-1558) a respeito da concepção de Cardano acerca da relação entre música e a alma. A despeito das diferenças de opinião, Ficino, Cardano e Escalígero pertencem ao mesmo universo discursivo, cujos contornos podem ser entendidos através da análise desta polêmica.

PALAVRAS-CHAVE: Girolamo Cardano - musica humana - música e medicina

ABSTRACT: Girolamo Cardano (1501-1576) has still not
attracted the scholarly attention he deserves for his theory
about the coincidence of music, medicine and mathematics.
As a music theorist and medical practitioner Cardano often
focuses on phenomena which he takes to be the most subtle
and hard to understand. Among these phenomena we find the
Platonic doctrine that music has the power to influence the
human body and soul. This paper explores Cardano's inter-
pretation of this specific doctrine by looking at his reception
of Galenic medicine, the tradition of musica humana, and es-
pecially Marsilio Ficino's theory of musical magic. Moreover,
it deals with Julius Caesar Scaliger's (1484-1558) criticism
*University of Warwick j.w.prins@warwick.ac.uk Tradução: Mônica Lucas e Delphim Rezende Porto 
1. Hieronymus Cardanus, De musica I é um manuscrito de 56 páginas, de ca. 1574, editado em: Hieronymi Cardani Mediolensis opera omnia (facsimile da edição de Sponius, Lyon, 1663; Stuttgart-Bad Cannstatt: Frommann, 1966; edição on-line: http://filolinux. dipafilo.unimi.it/Cardano/ testi/opera.html), vol. x. Para a tradução inglesa dos escritos teóricos de Cardano, cf. Clement A. Miller, Writings on music / Hieronymus Cardanus

([S.I.] : American Institute of Musicology, 1973).

2.

3. Descritas sobretudo em De subtilitatis (Nürnberg, 1550; Basel, 1554; Opera Omnia III). Para uma introdução na obra de

Cardano, cf.: Markus Fierz, Girolamo Cardano, 15011576: Physician, Natural

Philosopher, Mathematician, Astrologer, and Interpreter of Dreams (Boston et al.: Birkhäuser, 1983); para uma introdução em suas visōes médicas, cf.: Nancy

G. Siraisi, The clock and the mirror: Girolamo Cardano and Renaissance medicine

(Princeton, N.J.: Princeton University Press, 1997).

4. In common with many other educated men of the Renaissance Cardan was addicted to astrology and the occult." Miller,

Writings on Music (1973), p. 29. Com respeito à astrologia, cf.: Anthony Grafton, Cardano's cosmos: the worlds and works of a Renaissance astrologer (Cambridge, Mass. : Harvard UP, 1999). of Cardano's conception of the relationship between music and the soul. I will argue that whatever their differences of opinion, Ficino, Cardano and Scaliger belong to the same universe of discourse, whose contours can be understood through the analysis of their polemic.

KEYWORDS: Girolamo Cardano - musica humana - music and medicine

\section{INTRODUÇÃO}

Girolamo Cardano (1501-1576), erudito italiano universalmente conhecido, é autor de dois importantes tratados teóricos musicais, ambos adequadamente intitulados De musica (Sobre a música). ${ }^{1}$ Há anos estes ${ }^{2}$ dois escritos já deveriam constar entre as obras fundamentais para musicólogos e músicos devido às suas detalhadas discussões sobre a prática musical do séc. XVI. Até o momento, contudo, ainda não gozam da importância que merecem para a filosofia da música em geral, e, em especial para as ideias históricas da experiência musical. Como cientista, enciclopedista, astrólogo, médico e músico, Cardano estava, sobremaneira, interessado nas relações mais sutis do cosmos - as mais difíceis de pene$\operatorname{trar}^{3}$. Tais sutilezas, ainda distantes do campo de experiência da maioria dos musicólogos modernos, configuram razão para que ninguém ainda lhes tenha dedicado atenção mais ampla. Clement Miller, o mais influente musicólogo que se ocupou da teoria musical de Cardano, escreve, por exemplo, num tom depreciativo: "Tal como tantos outros homens educados do Renascimento, Cardano também se dedicou à astrologia e ao ocultismo" ${ }^{4}$. Portanto, não surpreende que o referido autor tenha passado inteiramente ao largo da teoria de Cardano sobre a imaginação musical, melancolia e da doença da gota justamente por se encontrar na intersecção entre a ciência, a astrologia e a magia.

Neste artigo, demonstro a importância que Cardano atribui à observação pessoal e à experiência - provenientes da doutrina platônica de que a música tem a força de influenciar profundamente tanto o corpo quanto a alma. Discorrerei sobre a modernização da crença tradicional na formidável força moral da música e tratarei de dois estudos de caso que versam 
sobre a força curativa da música no caso de melancolia e de gota para, em seguida, tratar da crítica do erudito Júlio César Escalígero (1484-1558) sobre a musicoterapia. Finalmente, resumirei, na conclusão, as modificações no pensamento sobre as influências da música no corpo e na alma na obra destes eruditos quinhentistas, definindo, especificamente, o papel que a experiência protagonizou nestas modificações.

\section{A reformulação de Girolamo Cardano da doutrina Pla-} TÔNICA SOBRE A FORÇA MORAL DA MÚSICA

Cardano estava a par de todas as histórias que circulavam há séculos sobre os poderes maravilhosos da música. Em primeiro lugar, contavam-se as histórias bíblicas - como aquela que relata como Davi curou o Rei Saul de sua doença ao toque de uma harpa (1 Samuel 16,23). Embora não fique totalmente claro para Cardano o que exatamente significaria a expressão “o espírito de Deus envolveu Saul”, ele estava convencido de que ali havia ocorrido uma perturbação psíquica $\mathrm{e}$, muito embora ele não precisasse qual instrumento Davi teria tocado, se uma lira ou uma harpa, e muito menos qual a afinação do referido instrumento ou qual tipo de música que nele soara, não havia dúvidas de que aquele tocar tenha sido tão poderoso a ponto de fazer o espírito maligno fugir de Saul, propiciando-lhe grande alívio e a recuperação da sua harmonia interna.

Assim como seu antecessor e inspirador Marsilio Ficino, Cardano estava sobretudo interessado na força maravilhosa que era atribuída à música da antiga Grécia. Ele estudou todos os mitos sobre este gênero nos seus menores detalhes. No De Institutione Musica ("Fundamentos da Música") de Boécio, que foi editado pela primeira vez no fim do séc. XV, ele pode, por exemplo, ler como Pitágoras trouxera um bêbado de volta à razão através de uma música adequada e como Orfeu com sua lira podia encantar não apenas pedras, árvores e animais, e até mesmo libertar sua amada Eurídice do submundo. Uma das histórias que causaram, de fato, impressão mais forte nele enquanto médico foi aquela de Ismênia de Tebas, que, através do som da música de flauta nos modos corretos, curava muitos habitantes de sua cidade, que sofriam diariamente de gota. ${ }^{5} \mathrm{Em}$ antigas teorias musicais mágicas,
5. Boethius, De institutione musica I.i, in: Calvin M. Bower en Claude V. Palisca (edição em língua inglesa), Fundamentals of Music (New Haven et al.: Yale U.P., 1989), pp. 1-8 (cf. p.6 para a musicoterapia no tratamento da gota). 
6. Cardano, Ars curandi parva: quae est absolutiss. medendi methodus parva medendi, apud. Siraisi, The clock and the mirror, p. 186. partia-se do princípio de que justamente a flauta era adequada para o tratamento da gota, pois consistia em uma afecção do fêmur, que tinha mais ou menos a mesma forma alongada de uma flauta. $\mathrm{Na}$ base para esta teoria, estava a crença de que todo o cosmos era animado, ou seja, que possuía uma alma e de que as coisas que entre si se assemelhavam exerciam uma força de atração umas sobre as outras. Através da mobilização dessa força de atração cósmica podiam ser tratadas, em cerimônias musicais, tanto afecçóes espirituais como corporais.

Ponto central da obra de Cardano é o questionamento do porquê da música do tempo de Davi, Pitágoras, Orfeu e Ismênia ser tão efetiva, ao passo que a música de seu próprio tempo era tão vazia e superficial e a procura por uma resposta a esta questão dominou-o por toda a vida. Difusas por todas as dez volumosas partes da opera omnia de Cardano encontramos referências à doutrina musical do ethos platônica, na qual se defende uma ligação direta entre música e as emoções humanas. Experiências nas quais a música é força moral e curativa tiveram importante papel na filosofia de Cardano e, nos vários exemplos que apresenta, o filósofo sempre procura estabelecer uma ligação entre as experiências musicais indiretas, tiradas de fontes históricas, e aquelas experiências musicais diretas, fundamentadas na vida cotidiana. A julgar pelos exemplos, parece claro, no que diz respeito à influência da música no corpo e na alma, que as estruturas narrativas tradicionais tiveram uma profunda influência na experiência de Cardano.

Em uma nota autobiográfica, datada de 1557, Cardano confessa ao leitor que ele, ao acordar de um sonho sobre uma bela música, subitamente compreendeu porque algumas pessoas morrem em virtude de febre e outras não. Isto era:

(...) Uma questão sobre a qual eu pensava há quase vinte e cinco anot. Por isto [...] eu comecei a escrever naquela mesma manhã aquele estimulante livro Ars parva medendi ["pequena arte medicinal] [...], que continha quase toda a totalidade da arte curativa. Assim, a harmonia era a precursora da sabedoria ${ }^{6}$.

Com estas palavras, Cardano lograva imitar retoricamente seus antecessores ilustres, como Galeno e Ficino, em modéstia, atribuindo a um sonho algo que ele poderia ter reivindicado para si. Ao mesmo tempo, porém, como Siraisi corretamente 
observou, ele utilizava esta forma retórica para dar à sua teoria médica uma aprovação mais elevada. ${ }^{7}$ De fato, em seu tempo, o conhecimento com base na revelação divina era considerado como mais digna de confiança do que o conhecimento obtido a partir da experiência própria.

Assim como Ficino e outros filósofos e eruditos do Renascimento, Cardano estudou detalhadamente a obra de Platão a fim de descobrir como exatamente a música poderia influenciar o homem. ${ }^{8} \mathrm{Tal}$ como seus predecessores, ele conhecia as famosas afirmações de Platão na República a respeito do papel especial reservado à música na educação de jovens. Neste diálogo, Platão se dedica a provar que, mesmo antes de uma criança ter capacidade de pensar logicamente, "[...] nada penetra mais fundo na alma e afeta-a mais fortemente do que o ritmo e a melodia. A música tem uma influência definitiva sobre a nossa conformação natural." Portanto, o contato com a música adequada na infância nos propicia um senso de beleza e um sentido moral - que é o fundamento desta afirmação. Crianças expostas à música adequada deverão "reconhecer e saudar a razão e abraçá-la com entusiasmo por terem estado em contato com a mesma através da sua educação".?

Cardano abraçou a meta de descobrir qual fora precisamente a música grega que "penetrava mais profundamente na alma", a ponto de as crianças poderem desenvolver uma harmonia interna profundamente enraizada, e tornarem-se cidadãos nobres, inteligentes e saudáveis. No séc. XVI, muito já havia sido descoberto a respeito da música da Antiguidade grega, e não era mais um total mistério o ponto preciso em que a sua força residia. Através do trabalho pioneiro de alguns notáveis teóricos musicais uma grande quantidade de informaçōes teórico-musicais e técnicas sobre aquela música havia emergido. Filósofos como M. Ficino estavam convencidos de que a redescoberta da chave para as forças mágicas e éticas da música da Antiguidade grega era, de fato, uma possibilidade real, bem como, também concordavam que, primeiramente, esta chave residia no estudo da afinação na qual a música grega era cantada ou tocada.

Os modos musicais gregos antigos com sua bem descrita ação sobre o espírito (ethos musical) constituíam a chave para a redescoberta da força encantatória da música. Uma indicação para este âmbito pode ser encontrada novamente na $R e$ -
7. Siraisi, The clock and the mirror, p. 186.

8. Um dos melhores estudos sobre a filosofia musical neoplatônica de Ficino permanese sendo: D.P. Walker, Spiritual and Demonic Magic from Ficino to Campanella (kopie Pennsylvania: The Pennsylvania state U.P., 2000; 1a. Ed. 1958) pp. 3-59. Para um estudo em holandês, cf: Jacomien Prins, 'Marsilio Ficino: hemelreiziger en geneesheer', in: Harmonisch labyrint, Prins en Teeuwen (eds.) (Hilversum: Verloren, 2007) pp. 77-94.

9. Plato, Politeia [República] 401e, trad. Gerard Koolschijn (Amsterdam: AthenaeumPolak \& Van Gennep, 1975), pp. 74-75. [trad. Português Monica Lucas e Delphim Porto Rezende] 
10. Plato, República 399ab, p. $72-73$.

11. Neste sentido, Cardano pode ser entendido como um antecessor de Rousseau, que, mais tarde, procurou transformar Emile em ser humano ideal, baseado concepções filosóficas moralmente elevadas. pública de Platão, na qual ele filosofa, ainda que timidamente, sobre a força da música. Platão pretendia, de uma vez por todas, declarar que a "música deve agir sobre a emoção, a sensibilidade, falta de autocontrole e coisas semelhantes". Pelo fato de a música lídia e jônica terem sido, em seu tempo, associadas a emoções incontroláveis, lascívia e fraqueza, ele pressupunha que estes modos musicais deveriam ser completamente banidos de seu Estado ideal. Os modos dórico e frígio, ao contrário, relacionados com o autocontrole e força de vontade, deveriam ser difundidos.

Penso que apenas a música [dórica] pode de maneira adequada educar a disposição de homens valentes para ações militares $[\ldots]$ que [...] em todas as circunstâncias se defenda da sorte com ordem e com energia. E também a música [frígia] que dispõe estas pessoas novamente para a vida cotidiana, para suas ações voluntárias, [...]: a disposição de homens [...] que [...] em todas as situaçōes se comporta com bom senso e moderação em todas estas circunstâncias, satisfeito com o que lhe sucede. A música, que imita admiravelmente as vozes de homens bem e malsucedidos, sensatos e corajosos, tanto em suas atividades obrigatórias quanto nas voluntárias, essa, deixa-a ficar. ${ }^{10}$

Ao unir essas duas citaçóes da República, Cardano chegou à conclusão de que deveria educar seus próprios filhos expondo-os desde a infância ao modo dórico, tranquilo e controlado, para desenvolverem-se como cidadãos equilibrados e responsáveis, e quando eles estivessem trilhando o caminho correto, estariam aptos a serem expostos à música estimulante e selvagem do modo frígio. Contudo, Platão, enquanto sábio teórico, apresenta uma teoria impactante sobre a ação da música, Cardano logo se depara com problemas que ele, como psicólogo experimental avant la lettre, encontra ao colocar em prática as propostas de Platão. ${ }^{11} \mathrm{O}$ maior obstáculo encontrado na educação musical de seus dois filhos foi que os cantores [professores de música] de seu tempo eram tão depravados, que mais desarmonizavam as almas do que as colocavam no bom caminho. Embora decepcionado, Cardano, relata este experimento com suas próprias crianças, expondo inicialmente a seguinte visão platônica e aristotélica: 
A Música é valiosa por constituir uma maneira aprazível de descanso, e por que é acima de tudo útil para a [fortalecer a] disciplina e como um valor cultural na vida humana. E também, por gerar prazer sem consequências negativas, a música é recomendável para o bem estar de todos, em especial das crianças.

Em seguida, porém, o autor muda subitamente de tom:

Se considerarmos a complexidade do canto atual, no qual várias pessoas cantam simultaneamente - [um tipo de música] que não é possível ser executada solitariamente, e levando em conta a presença necessária de outros cantores, dos quais muitos tem um estilo de vida dissoluto, é necessário concluir que esta prática [musical] não é útil a ninguém. Hoje em dia, quase não é mais possível encontrar um músico que não seja culpado de todo o tipo de comportamento indecente, e por isto este tipo de músico consiste no maior entrave [...] para todos os homens em geral. Porque não se encontra, entre os homens mais destacados de nosso tempo, como Erasmo [...] e Vesalius, nenhum músico?

Quando fazem música em casa, os cantores [...] empesteiam o caráter de nossas crianças e adolescentes, já que a maior parte deles é beberrona e glutona, e eles são devassos, inconstantes, impacientes, grosseiros, preguiçosos e acometidos de todas as formas de apetites indecentes. Os melhores dentre eles são tolos.. ${ }^{12}$

A realização prática de um Estado utópico cheio de homens bem afinados é, de acordo com Cardano, em seu tempo, por definição, destinada a falhar - pois o espírito deturpado daqueles cantores torna impossível atingir uma música fundada na pureza. Além da depravação geral, estes cantores italianos do séc. XVI não eram nem mesmo capazes de cantar no temperamento pitagórico, absolutamente necessário para dar nova vida aos modos gregos antigos, com sua maravilhosa ação sobre a psique humana.

Cardano, no entanto, permanece otimista acerca da possibilidade da consciência do homem atual, mediante auxílio da música adequada, recuperar o estado harmônico original, no qual o homem é um com o cosmos. Completamente em sintonia com o pensamento neoplatônico, Cardano permanece convencido de que um mundo mais harmonioso se esconde atrás da realidade visível e audível, e que este é mais real do que tudo que um homem experimenta em sua vida cotidiana.
12. Cardano, De Subtilitate $\mathrm{XVI1}$, in Opera Omnia III 
13. Para a maneira como Cardano procurou se purgar deste fato através de uma análise de seus sonhos, cf.: Fierz, Girolamo Cardano, pp. 145vv.

14. Para a história do pensamento ocidental acerca da musicoterapia, cf. Werner F. Kümmel, Musik und Medizin: ihre Wechselbeziehungen in Theorie und Praxis von 800 bis 1800 (Freiburg [Breisgau] [etc.]: Alber, 1977); Peregrine Horden (ed.), Music as Medicine:

The History of Music

Therapy Since Antiquity (Aldershot [etc.]: Ashgate, 2000); Penelope Gouk (ed.), Musical Healing in Cultural Contexts (Aldershot [etc.]: Ashgate, 2000).
A crença, porém, de que algo desta verdade possa ser ouvida ainda durante a nossa permanência na terra - através de um revival da música grega antiga - é seriamente colocado em prova na prática cotidiana.

O projeto falho de educação musical de seus filhos perdurará, como uma maldição, por toda a vida de Cardano - especialmente pelo fato de seu filho mais velho, após o assassinato de sua esposa, em 1560, ter cometido suicídio. ${ }^{13}$ Mesmo após este episódio pungente de sua vida, o filósofo permanece inabalável na crença em um poder moral e curativo da música, aprofundando-se na investigação da música instrumental - já que os instrumentistas geralmente têm um caráter melhor e, sobretudo, porque estes instrumentistas poderiam reproduzir mais rigorosamente os modos gregos.

\section{A visão de Cardano sobre a aÇÃo medicinal da música SOBRE O CORPO E O ESPÍRITO}

Cardano é herdeiro de um sistema complexo, no qual a música pode ser aplicada de diversas maneiras para gerar saúde espiritual e corporal tanto para curar doenças psíquicas quanto somáticas. ${ }^{14}$ Dentro deste sistema, a maldade é associada à doença e à fealdade, e a bondade, à saúde e à beleza. Embora este sistema não seja definido mais claramente, senão na filosofia, a partir de diversas passagens sobre o poder curativo da música, fica claro como esta [disciplina] está espalhada por toda a obra de Cardano que, em grandes linhas, coincide com a visão de mundo mágico-musical de Ficino. Nesta concepção, o universo é regido por forças harmônicas cósmicas, no qual as partes dotadas de espírito - das quais o mundo é constituído - se atraem ou se repelem sob a forma de 'simpatia' ou 'antipatia'. Por consequência, há um aumento de harmonia, manifesta no cosmos como crescimento, e decadência, no florescimento da dissonância. Assim como o cosmos, o homem é refém destas forças cósmicas. A música, como forma de energia cósmica ambivalente, pode tanto ser utilizada como um meio calmante quanto estimulante, que opera alterações no corpo e na alma. A influência calmante da música frequentemente era associada com o modo musical dórico e, a estimulante, com o modo frígio. Quando utilizada como meio homeopático, a música era aplicada proporcionalmente às características da doença. De outro modo, 
quando utilizada de maneira alopática, a música era prescrita com caráter oposto ao tipo de doença.

Um médico segundo a musicoterapia renascentista deveria saber prescrever não apenas possuindo um conhecimento sólido da música, mas sobretudo ser bem instruído na arte curativa humoral, na qual quatro tipos humanos (colérico, sanguíneo, flegmático e melancólico) eram associados a quatro fluidos corporais - que correspondiam a quatro elementos cósmicos e suas qualidades básicas (Diagrama 1). ${ }^{15}$

\begin{tabular}{|c|c|c|c|c|}
\hline $\begin{array}{c}\text { Cosmos } \\
\text { Elemento }\end{array}$ & $\begin{array}{l}\text { Qualidade } \\
\text { Básica }\end{array}$ & $\begin{array}{l}\text { Homem } \\
\text { Fluido } \\
\text { corporal }\end{array}$ & $\begin{array}{c}\text { Tempera- } \\
\text { mento }\end{array}$ & Música \\
\hline $\begin{array}{c}\text { Fogo } \\
\text { (soprano) } \\
\text { [frígio] }\end{array}$ & $\begin{array}{l}\text { seco e } \\
\text { quente }\end{array}$ & $\begin{array}{c}\text { bile } \\
\text { amarela }\end{array}$ & colérico & $\begin{array}{c}\text { agudo } \\
\text { estimulante }\end{array}$ \\
\hline $\begin{array}{c}\text { Ar } \\
\text { (alto) }\end{array}$ & $\begin{array}{l}\text { quente e } \\
\text { húmido }\end{array}$ & sangue & sanguíneo & $\begin{array}{l}\text { médio } \\
\text { agudo }\end{array}$ \\
\hline $\begin{array}{l}\text { Água } \\
\text { (tenor) }\end{array}$ & úmido e frio & muco & flegmático & médio grave \\
\hline $\begin{array}{c}\text { Terra } \\
\text { (dórico) }\end{array}$ & frio e seco & bile negra & melancólico & $\begin{array}{c}\text { grave (baixo) } \\
\text { Calmante }\end{array}$ \\
\hline
\end{tabular}

Diagrama 1: Uma visão esquemática das três esferas harmônicas interligadas (cosmos, homem e música) e seu universo.

Enquanto o principal interesse de Ficino era a imortalidade da alma de seus pacientes e sua terapia musical apontava para a cura de sua alma, Cardano, mais do que seu antecessor, também estava profundamente interessado no Homem como um tipo especial de animal. ${ }^{16}$ Este interesse na fisiologia humana influencia seu pensamento acerca da terapia musical. No décimo primeiro e décimo segundo livros de sua conhecida obra De subtilitate ('Sobre a sutileza'), Cardano descreve, por exemplo, detalhadamente a função dos sentidos interiores (ou as 'capacidades do ânimo') humanos, que estão localizados em partes específicas do cérebro. $\mathrm{O}$ autor parte do pressuposto que pela audição musical são produzidas imagens auditivas na imaginação e em seguida são armazenados na memória, que, pelo seu caráter duradouro, pode exercer grande influência no corpo e na alma. Ele segue aqui, em primeira instância, uma interpretação medieval de Aristóteles,
15. Hippocrates ( 460 tot 377 v. C.) é visto como o fundador da assim chamada medicina humoral. Ele partia do princípio de que, pra atingir a boa saúde, é necessário um equilíbrio dos quatro humores (líquidos corporais). Métodos de tratamento se voltavam para obter esta proporçãa. Nesta forma de medicina,purgações, jejum, alimentação adequada, descanço, movimento, ervas e também a músicoterapia tinham grande importância no tratamento de doenças. Cf. Kümmel, Musik und Medizin, pp. 131-156.

16. Cardano, De subtilitate xi, p. 550. 
17.Fierz, Girolamo Cardano, p. 132.

18. Embora a representação de Fludd seja de data posterior, ela pode, no meu entender, servir bem como ilustração da concepção neoplatônica da alma humana, uma vez que Fludd compartilhava desta com seu antecessor. através do ponto de vista da ciência médica de Galeno. Em seu De anima ["sobre a alma"], o estagirita havia afirmado que as diversas partes do cérebro são acometidas por cinco processos mentais específicos: 1) o sentido comum (no qual o input de todos os sentidos é reunido); 2) a imaginação; 3) a fantasia; 4) a capacidade de julgamento (que não deve ser confundida com o discurso); 5) a memória ${ }^{17}$.

Cardano travou contato com esta teoria durante seu estudo da medicina. Esta doutrina aristotélica do conhecimento foi, a seguir, incorporada em uma teoria neoplatônica sobre a alma humana. Desta maneira, pôde escrever detalhadamente sobre aspectos fisiológicos de funções e processos mentais e, sobretudo, relacioná-los com o mundo metafísico da alma imortal (mundus intellectualis) e o da imaginação (mundus imaginabilis) (Ilustração 2) ${ }^{18}$.

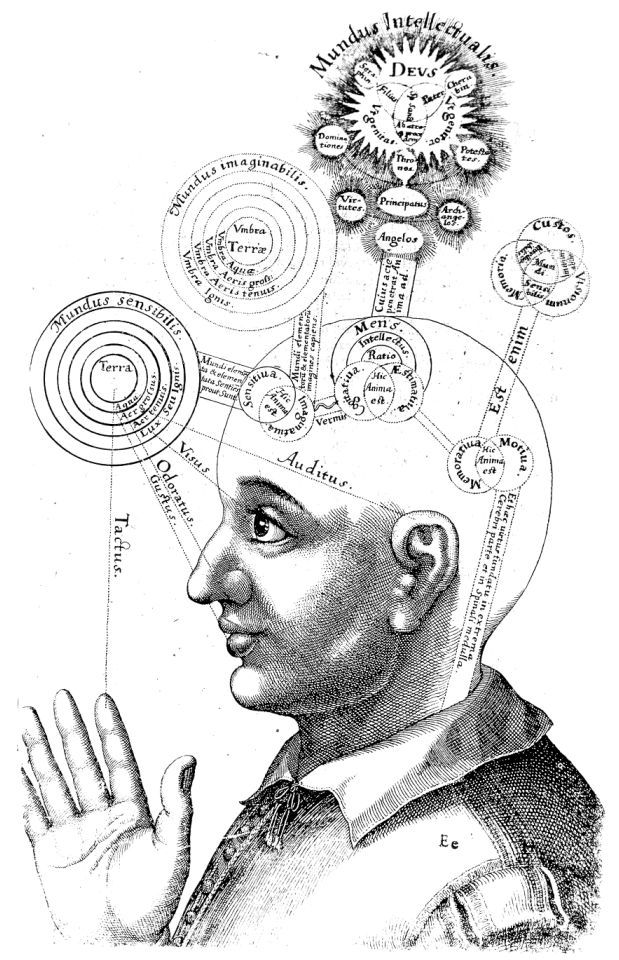

Ilustração 1: uma representação do cérebro espiritual, que é intermediário entre o mundo físico e metafísico. Proveniente de: Robert Fludd, Utriusque cosmi maioris scilicet et minoris historia II.i. (Oppenheim, 1619), 217. 
Cardano se dá conta de que a música que penetra no cérebro por via do ouvido (auditus), mobiliza imediatamente a imaginação. Em primeira instância a música faz uso da imaginação que, assim como as paixões (emoções) humanas, pode tecer uma ponte entre o corpo e a alma. Através do uso da imaginação musical - tanto pela audição da música quanto pela lembrança de música, por exemplo, em sonhos musicais - esta força pode exercer influência direta seja sobre os quatro humores corporais (entre eles o sangue) seja sobre as capacidades espirituais mais elevadas. Deste modo, a música harmônica com um ritmo ordenado poderia exercer influência direta sobre o batimento cardíaco. Quando a circulação sanguínea e o batimento cardíaco funcionam bem, há uma influência positiva sobre o bem estar psíquico e físico e assim, a música harmônica poderia agir mais profundamente.

Antes de se compreender a função do sistema nervoso central, teorizava-se sobre a influência do espírito no corpo, e vice-versa, frequentemente em termos de pneuma ou spiritus. ${ }^{19}$ Spiritus, como 'energia-substância' intermediária entre corpo e alma era utilizada em todas as explicaçóes a respeito da interação entre corpo e alma. Ao fim do séc. XVI, Ficino transformou a noção de spiritus em um pilar de suas ideias sobre a medicina musical. ${ }^{20}$ Ele afirmara que, tal como o cosmos e o homem, também a música era dotada de spiritus, e que, na escuta musical era possível, literalmente, recarregar a alma com o spiritus (energia). O filósofo tornou-se muito popular com sua teoria sobre a força maravilhosa curativa da música em pacientes em quem havia sido diagnosticada "melancolia" (acometimento de bile negra). Nessa filosofia, a melancolia estava associada a todo tipo de afecção mental causada por um excesso de bile negra bem como com um tipo humano que pudesse possuir especial inteligência e criatividade. Esta ambiguidade é provavelmente a origem da enorme popularidade da "melancolia" entre eruditos quinhentistas. Cardano participa também desta moda, e trata da doença especialmente na sua mais popular obra: De subtilitate. Como médico profissional, ele formula sua própria diagnose deste mal:

Entre aqueles cujos corpos são quentes e úmidos [o tipo sanguíneo, cf. Diagrama 1], homens inteligentes têm a pior disposição, a menos que se dediquem ao estudo da filosofia. Uma das consequências de seu estudo é verdadeiramente a melancolia. Ela é
19. Para teorias médicas sobre pneuma e spiritus, cf.: Gerard Verbeke, L'Évolution de la Doctrine du Pneuma: Du Stoicisme à $S$. Augustin: Étude Philosophique (Paris [etc.]: Desclée De Brouwer [etc.], 1945); para a recepção destas teorias na Renassença, cf.: Nancy Siraisi, History, Medicine, and the Traditions of Renaissance Learning (Ann Arbor: Univ. of Michigan Press, 2007).

20. Walker, Spiritual and Demonic Magic from Ficino to Campanella, pp. 3-11. 
21. Cardano, De subtilitate xii, p. 558.

22. Deusa do amor, que está geralmente associada na músico terapia astrológica, junto com o planeta Venus, àos prazeres

"baixos" e à qual estão associados o modo lídio e a música sedutora.

23. Cardano, De subtilitate xii, p. 558.

24. Para uma lista de exemplos da terapia musical de Cardano no tratamento de afecçooes físicas e psíquicas que sustentam esta tese, $\mathrm{cf}$. Kümmel, Musik und Medizin, p. 465 (verbete: Cardano, Girolamo). causada pela liberação de seus humores gordurosos [bile negra], como consequência de estudos e vigílias extravagantes. Todavia, mesmo sendo homens inteligentes, eles perseveram em seus hábitos maus e viciosos, então, não podemos constatar outra coisa que eles ajam em linha com seu caráter, e que o estudo da filosofia não tenha trazido a eles nenhum proveito ${ }^{21}$.

Com base tanto na investigação própria como na observação de seus pacientes, Cardano certamente deve ter sabido que nenhuma erva era eficaz contra um certo tipo de depressão sombria. Contra o seu próprio julgamento, Cardano assume as ideias terapêuticas otimistas de Ficino e especula sobre a melancolia em termos de um excesso de bile negra, gerada por hábitos e pensamentos de longa duração - em que a circulação sanguínea é estagnada e é explorado um excesso de energia vital (spiritus). Graças a seu ceticismo, Cardano aguça ainda mais este diagnóstico e, tal como Ficino, apresenta um remédio surpreendentemente simples para este mal.

Por causa de suas atividades intelectuais, homens inteligentes são menos escravizados por Vênus, ${ }^{[22]}$, porque o estudo desperdiça o spiritus animalis [a energia vital que é utilizada para os processos cerebrais], desviando-os do coração para o cérebro, ou seja, na direção contrária dos órgãos sexuais. Com isto, estes homens geram crianças fracas que não se assemelham de modo algum a eles. Eles tirarão enorme proveito se procurarem a companhia de mulheres belas, pela leitura de histórias de amore e pendurando em seus quartos de dormir retratos de moças bonitas ${ }^{23}$.

Homens que sofrem de melancolia - por permanecerem demais 'com seus pensamentos') - tirarão, portanto, proveito de todas as ocasióes possíveis em que a sua imaginação seja estimulada. $\mathrm{O}$ contato direto com todos os tipos de assuntos sugestivos que estimulam a imaginação favorecem uma circulação sanguínea mais rápida e um batimento cardíaco mais rápido. Como consequência, substâncias nocivas - como a bile negra - deixariam o corpo, e substâncias curativas, como a energia (spiritus), entrariam no mesmo. Embora Cardano não examine, neste contexto, a música estimulante, em seus escritos são apresentados vários exemplos da ação medicinal da música estimulante, nos quais ele parece pensar da mesma maneira ${ }^{24}$. Enquanto Ficino discorre sobre o poder medicinal 
da música em termos das influências das forças cósmicas sobrenaturais, Cardano parece estar muito mais interessado na força afectiva da música, ou seja, nos modos como a imaginação e as emoções podem ser incitadas e manipuladas. Em sua terapia musical, a definição de spiritus é desviada da esfera metafísica para a fisiológica: spiritus não é então mais utilizado para explicar a intervenção de anjos e demônios, mas, sim, para descrever fenômenos vitais em termos naturais. Este novo focus traz para o primeiro plano a maneira como Cardano acredita ser possível tratar afecções - como a gota - através da música ${ }^{25}$, e, outra vez, podemos aqui verificar o quanto as experiências pessoais do filósofo com esta doença são influenciadas pela tradição da terapia musical ${ }^{26}$

A gota é descrita, em seu tempo, com termos semelhantes aos da melancolia. A gota é de um lado um mal doloroso, mas, por outro, um presente, já que alguém que sobrepuja este mal tem a chance de se tornar um ser melhor. ${ }^{27}$ Considerando o pano de fundo da medicina humoral (cf. Diagrama 1) que é tanto moralística quanto holística, isto não é surpreendente: não há nenhuma diferença sensível entre corpo e alma, nem entre doença e depravação. Cardano define 'gota' como uma doença do metabolismo, na qual elementos nocivos, assim como o excesso de bile amarela e muco bloqueiam partes diversas do corpo - o que frequentemente gera uma dor torturante. Tradicionalmente, a musicoterapia prescrevia para este mal, no sentido homeopático, uma música estimulante (frígia) que pudesse colocar em movimento o excesso de elementos nocivos, de modo a aliviar a dor. ${ }^{28}$ Ao contrário, Cardano ao sugerir a aplicação alopática (ação curativa na qual são utilizados meios com ação contrária [à causa]), de uma música calmante e apaziguante que deveria ser tocada por um instrumento de corda de som suave (Ilustração 3), demonstra, com base na sua experiência prática, que a música estimulante pode agir de modo tão perturbador que pode apenas aumentar a dor do paciente. ${ }^{29}$
25. Para a história da músicoterapia no tratamento da gota, cf.: Kümmel, Musik und Medizin, pp. 353vv.

26. Para modelos narrativos na obra de Cardano, cf.: Siraisi, The Clock and the Mirror, pp. $195 \mathrm{vv}$.

27. Cardano escreve um elogio à gota, intitulado Podagrae Encomium. Ele parece ainda ter sofrido desta doença; cf. Siraisi, The Clock and the Mirror, p.323.

28. Kümmel, Musik und Medizin, p. 354.

29. A página título do Solatium podagricorum de Balde ilustra que esta é a visão corrente, um século após: o flautista cedeu seu lugar ao deus Apolo e sua lira. 


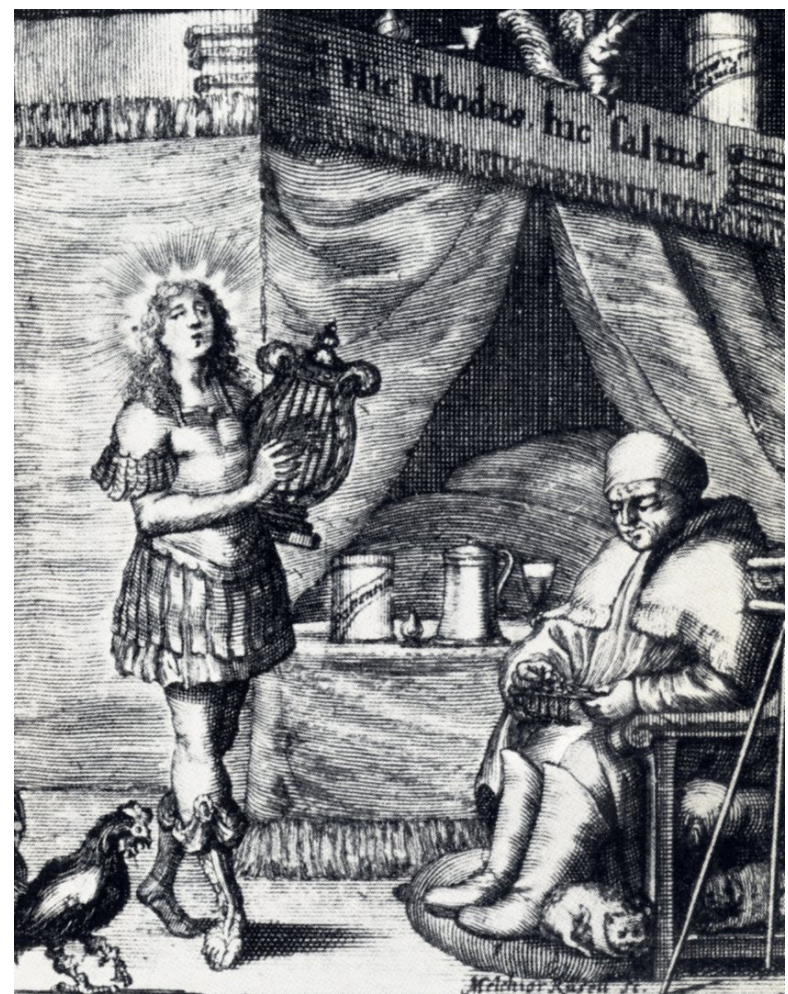

Ilustração 2: Página Título de Jacob Balde, Solatium podagricorum ("Um remédio contra a gota”) (München, 1661).

Cardano provavelmente acreditava que uma música tranquila, como tal, poderia distrair o paciente de modo que suas queixas de dor diminuírem. Além disto, a audição musical poderia incrementar também a potência energética (o estoque de spiritus) no corpo, o que, mesmo que temporariamente, seria o primeiro passo no processo de reequilíbrio corpóreo.

30. Julius Caesar foi o pai de um erudito ainda mais famoso, Josephus Justus Scaliger, que em 1593 foi adimitido como professor na Universidade de Leiden.

\section{A crítica de Júlio César Escalígero sobre a terapia mu- SICAL DE CARDANO}

Júlio César Scalígero ${ }^{30}$, um influente contemporâneo de Cardano, critica-o duramente em Exotericarum exercitationum libri $X V$ de subtilitate ad Hieronymum Cardanum (1557) ("Exercícios sobre a compreensão exotérica geral dos quinze livros sobre o De subtilitate de Girolamo Cardano"), em que ele combate a concepção, em sua visão, esotérica, de Cardano. Entre estas concepçôes encontra-se também a reformulação de 
Cardano da doutrina platônica, segundo a qual a música pode ter uma força curativa sobre o corpo e a alma. Escalígero procura, com base no juízo saudável, experiência e observação, um conhecimento mais seguro do mundo e do homem. Embora Cardano e J. C. Escalígero sejam apresentados, com base em seu debate histórico como representantes respectivamente, do pensamento mágico e da ciência natural, na literatura secundária, é possível afirmar que no caso de queixas corporais, como a gota, ambos se dedicavam a temas semelhantes e compartilhavam frequentemente da mesma opinião ${ }^{31}$.

J.C. Escalígero observa, com razão, que Cardano, por conta de seu grande conhecimento da tradição médica, assim como pensadores anteriores a ele neste campo, escreve em latim, e estaria, por essa razão, fechado em um universo de visóes tradicionais, e, dentre estas, está aquela que atribui à música uma força maravilhosa. Escalígero culpa Cardano indiretamente de sua repetição irrefletida da história de Ismênia de Tebas, sem se perguntar se realmente a música pode realmente conter spiritus, bem como de não testar se a gota é de fato originada pelo spiritus. Embora sua crítica seja em parte verdadeira, ele não compreendeu totalmente a concepção 'sutil' de Cardano acerca da música e do spiritus. Isto não é totalmente surpreendente, uma vez considerado que Cardano utiliza o conceito spiritus como uma espécie de palavra mágica e em diversas explicações médicas de coisas 'sutis', que mesmo entendida rigorosamente como percepção fina, ainda é de difícil compreensão.

$\mathrm{Na}$ terapia musical de Cardano a respeito da gota, subjaz a crença básica de que o preenchimento da 'energia vital' tem um efeito curativo sobre o corpo e sobre a alma. Escalígero, contudo, a interpreta como se Cardano tivesse afirmado que a esconjuração do spiritus causaria alívio ou cura da gota, e faz uma crítica afiada a esta visão, pois:

Se a gota consistisse exclusivamente de spiritus, a dor poderia ser dissipada pela remoção [dos spiritus da parte dolorida]. Como, contudo, a substância corporal é dura, fria e pouco fluida, não é possível de modo algum falar em cura, uma vez que pelo desvio dos spiritus por consequentemente, a substância corporal se tornará ainda mais dura. Mas aprendemos dos filósofos e médicos que a dor pode ser combatida de três maneiras: 1) através do desligamento própria dor, com meios que a combatam; 2) por
31. Esta é também a visão de Ian Maclean, que se aprofundou no debate entre Cardano e Scaliger. Cf.: 'The interpretation of natural signs: Cardano's De subtilitate versus Scaliger's Exercitationes', in: Brian Vickers (ed.), Occult and Scientific Mentalities in the Renaissance (Cambridge: Cambridge U.P., 1984), pp. 231-252; e idem, 'Cardano's Eclectic Psychology and its Critique by Julius Caesar Scaliger', in: Vivarium 46.3. (2008), pp. 392-417. 
32. J.C. Scaliger, Exotericarum exercitationum libri XV de subtilitate ad Hieronymum Cardanum, Frankfurt a. M., 1592, p.1084.

33. Para a influência de Cardano em Johannes Kepler, cf. Judith V. Field, 'The relation between geometry and algebra: Cardano and Kepler on the regular heptagon', in: Girolamo Cardano: Philosoph, Naturforscher, Arzt, Eckhard Kessler (ed.), (Wiesbaden: Harrassowitz Verlag, 1994), pp. 219-242. Vale notar que Escalígerotambém influenciou Johannes Kepler. meios que eliminem a origem [da dor]; ou 3) tornando a parte do corpo afetada insensível, ou seja, reintroduzindo spiritus novamente nela [...]. Daí se deduz que aplicar este método é impossível, como ele [Cardano] afirma, para curar a gota frequentemente, ou [mais precisamente] curá-la definitivamente ${ }^{32}$.

Escalígero não apenas demonstra que não compreendeu Cardano totalmente. A citação acima demonstra que sua experiência médica estava tingida por interpretaçôes contrárias à medicina humoral. Escalígero parte do pressuposto - que mais tarde seria a direção mais aceita na 'medicina regular' - que as afecçóes corporais devem ser tratadas em termos puramente materiais. Não se trata [no caso de Cardano] de uma medicina como ciência, direcionada a todas as características dos homens e das doenças. Cardano parte de uma visão holística do homem, que mais tarde constituirá a base da "medicina alternativa" e da psicoterapia, segundo as quais afecçōes corporais são discutidas em termos psicossomáticos. Trata-se de medicina como uma arte, na qual as doenças podem ser interpretadas e tratadas no contexto do histórico pessoal do paciente. Ele afirma que só é possível discorrer seriamente sobre as possibilidades da musicoterapia a partir desta última perspectiva.

\section{Conclusão}

Independentemente das exatas diferenças de opinião sobre a terapia musical, no caso da gota, a partir do debate entre Cardano e J. C. Escalígero, fica evidente que ambos os filósofos compartilhavam o mesmo discurso, cujo contorno apenas é coerente quando suas concepções são comparadas entre si. Nos dois eruditos fica claro, em primeiro lugar, que suas experiências pessoais são determinadas por suas tradiçôes filosóficas, médicas e musico-teóricas.

No espírito da Renascença, ambos os autores compartilhavam da ambição de revelar os segredos do cosmos harmônicos e apresentá-los a um público mais amplo. ${ }^{33}$ Tanto o De subtilitate de Cardano quanto o Exotericarum exercitationum de Escalígero são testemunhos da chegada de uma visão científica empírica relativamente nova a respeito do mundo e seus habitantes. Na obra de Cardano, esta visão toma forma em novas perguntas a respeito da força maravilhosa da música, 
e em novas respostas à velhas perguntas sobre esta doutrina. Em intensidade crescente, ele procurou explicar a influência da música sobre o ser humano em termos fisiológicos. Além disto, ele desviou sua atenção da influência sobrenatural para a influência afectiva da música. No debate com Scaliger, isto levou finalmente a uma melhor compreensão de fenômenos difíceis de fundamentar, como a imaginação musical, a melancolia e a gota.

Gostaria de agradecer aos meus colegas Mônica Lucas, Delphim Rezende Porto e Juliana Vasques pela tradução e revisão deste artigo.

\section{REFERÊNCIAS BIBLIOGRÁFICAS:}

\section{Fontes Primárias}

BOETHIUS. De Institutione Musicali. In: CALVIN M. Bower en Claude V. Palisca (edição inglesa), Fundamentals of Music (New Haven et al.: Yale U.P., 1989).

ESCALÍGERO, Júlio César. Exotericarum exercitationum libri $X V$ de subtilitate ad Hieronymum Cardanum, Frankfurt a. M., 1592.

Hieronymi Cardani Mediolensis opera omnia (facsimile-uitgave van de Sponius-uitgave, Lyon, 1663; Stuttgart-Bad Cannstatt: Frommann, 1966; online editie: http://filolinux. dipafilo.unimi.it/Cardano/testi/opera.html).

PLATO. Politeia. traduzida por Gerard Koolschijn. Amsterdam: Athenaeum-Polak \& Van Gennep, 1975.

\section{Literatura Secundária}

FIELD, Judith V. The relation between geometry and algebra: Cardano and Kepler on the regular heptagon', In: Girolamo Cardano: Philosoph, Naturforscher, Arzt, Eckhard Kessler (ed.). Wiesbaden: Harrassowitz Verlag, 1994, p. 219-242. 
FIERZ, Markus. Girolamo Cardano, 1501-1576: Physician, Natural Philosopher, Mathematician, Astrologer, and Interpreter of Dreams. Boston et al.: Birkhäuser, 1983.

GOUK, Penelope. (ed.) Musical Healing in Cultural Contexts. Aldershot [etc.]: Ashgate, 2000.

GRAFTON, Anthony. Cardano's cosmos: the worlds and works of a Renaissance astrologer. Cambridge, Mass.: Harvard UP, 1999.

HORDEN, Peregrine (ed.), Music as Medicine: The History of Music Therapy Since Antiquity. Aldershot [etc.]: Ashgate, 2000.

KÜMMEL, Werner F. Musik und Medizin: ihre Wechselbeziehungen in Theorie und Praxis von 800 bis 1800. Freiburg [Breisgau] [etc.]: Alber, 1977.

MACLEAN, Ian. The interpretation of natural signs: Cardano's De subtilitate versus Scaliger's Exercitationes. In: Brian Vickers (ed.), Occult and Scientific Mentalities in the Renaissance. Cambridge: Cambridge U.P., 1984, p. 231-252.

Cardano's Eclectic Psychology and its Critique by Júlio César Escalígero'. In: Vivarium 46.3. (2008), pp. 392-417.

MILLER, Clement A., Writings on music / Hieronymus Cardanus. [S.I.]: American Institute of Musicology, 1973.

PRINS, Jacomien. Marsilio Ficino: hemelreiziger en geneesheer. In: Harmonisch labyrint, Prins en Teeuwen (eds.). Hilversum: Verloren, 2007, p. 77-94.

SIRAISI, Nancy G. The clock and the mirror: Girolamo Cardano and Renaissance medicine. Princeton, N.J.: Princeton University Press, 1997.

History, Medicine, and the Traditions of Renaissance Learning. Ann Arbor: Univ. of Michigan Press, 2007.

VERBEKE, Gerard. L'Évolution de la Doctrine du Pneuma: Du Stoicisme à S. Augustin: Étude Philosophique. Paris [etc.]: Desclée De Brouwer [etc.], 1945. 
WALKER, D.P. Spiritual and Demonic Magic from Ficino to Campanella. Kopie Pennsylvania: The Pennsylvania state U.P., 2000, primeira edição 1958. 